\title{
Inversion analysis of strength parameters of loess cutting high slope in Jijiayuan, Shanxi
}

\author{
$\mathrm{Yu} \mathrm{Xi}{ }^{1, *}$, Jifei Zhao ${ }^{2}$, and Gang $\mathrm{Li}^{1}$ \\ ${ }^{1}$ Shaanxi Key Laboratory of Safety and Durability of Concrete Structures,, NO.1 Xijing Road, Xi an 710123, China. \\ ${ }^{2} \mathrm{XI}$ 'an shiyou university, NO.18 Electronic Second Road, Xi' an 710065, China.
}

\begin{abstract}
In the process of analyzing the stability of loess slope, determining the value of strength parameter $c$ and $\varphi$ is a much more complex problem, and there is not mature and systematic method. In this paper, the inverse analysis of the value $c$ and $\varphi$ in Shanxi Jijiayuan cutting loess slope, about 51.6m, by bishop method and Spencer method based on the statistical strength indexes. To analyze the stress of the slope used finite element and compare the inverse result and test data. The result indicates the value of $\mathrm{c}$ will control the stability of slopes in $\mathrm{Q}_{3}$ layer, and the value of $\varphi$ will control the stability of slopes in $\mathrm{Q}_{2}$; the inverse result is close to the result with direct shear test when the moisture content is sample's plastic limit moisture content. we can select strength parameters obtained though the direct and quick shear under the conditions that the soil sample's moisture content is plastic limit moisture content for evaluation the slope stability. For the high slope, it should be cautious to select the $\varphi$ in the lower part.
\end{abstract}

\section{Introduction}

The stability of loess slope is one of the main engineering geological problems in loess area. At present, the main methods of slope stability analysis and evaluation include non-deterministic analysis, qualitative analysis and quantitative analysis ${ }^{[1]}$. Qualitative analysis methods include natural historical analysis method, engineering analogy method, graphic method ${ }^{[2]}$,etc. Although natural historical analysis method can only draw qualitative conclusions, it is the basis of other methods. Limit equilibrium analysis and finite element method $^{[3]}$ are quantitative analysis methods, which can directly provide necessary parameters for engineering design, and are the main means of slope stability analysis.

In recent years, through the introduction and intersection of some new disciplines and theories, some new non-deterministic slope stability analysis methods have been gradually formed, such as reliability analysis method, fuzzy comprehensive evaluation method, and neural network evaluation method ${ }^{[4-6]}$.

Slope stability analysis is a relatively complex problem, affected by various uncertain factors, such as the complexity of geological conditions, the deviation of the calculation model and the certain error between the selection of calculation parameters and the actual, so that the slope stability analysis method is still in the stage of research and exploration at present. As the loess is windformed under arid and semi-arid conditions, showing strong structure and extremely sensitive to water, the influencing factors of slope stability analysis are mainly manifested in the uncertainty of strength parameters $c$ and $\varphi^{[7]}$. Therefore, in the concrete work, how to select the strength parameters is a difficult point in the stability analysis of loess slope, which directly relates to the accuracy and reliability of the calculation results.

Inversion method is a very feasible method to determine the strength parameters of loess slope. In the 1970s, Karanagh.K and Clough.R proposed the geotechnical parameter inversion theory in the finite element method of inverse calculation of elastic modulus ${ }^{[8]}$. In 1980, Gioda used the simplex optimization method to solve the elastic and elastoplastic mechanical parameters of rock mass ${ }^{[9]}$. Sakurai proposed the inverse solution method for inverse calculation of in-situ stress and elastic modulus of tunnel surrounding rock ${ }^{[10]}$. Chen Baocai et al. ${ }^{[11]}$ used the inversion method to analyze and evaluate the stability of an expressway slope, and provided a basis for landslide treatment. Wang Huiting et al. ${ }^{[12]}$ calculated the slope stability coefficient based on the inversion results of soil strength parameters, and the calculation results showed that the inversion results were close to the actual situation. Gong Yufeng et al. ${ }^{[13]}$ carried out mechanical parameter inversion analysis of complex structures and got good results.

According to the "limit state slope" theory, a landslide is a proven destructive slope, that is, at the moment of sliding, the stability coefficient decreases from greater than 1 to less than $1^{[14]}$. Using the data of the loess slope that has undergone landslides, the shear strength parameters of the slope can be obtained by inversion, and the inversion results can be fed back to the actual engineering application or the selection of indoor testing scheme, which is an effective method to solve the selection of the strength parameters of the loess.

\footnotetext{
* Corresponding author: 20190015@xijing.edu.cn
} 
Taking Shanxi G209 national road home tableland cutting landslide as an example, the original slope as the limit state of slope, see is 1 , the slope stability coefficient of landslide in the area, on the basis of statistical indicators, the loess cutting slope is obtained by using the inversion method involved in the soil of different $\mathrm{c}, \varphi$ values.

The slope stability parameters can be obtained through inversion, and the inversion calculation results can be fed back to the actual engineering, which provides a reference for the reasonable selection of stability parameters for engineering design and construction in the future.

\section{Engineering geological conditions}

Jijiayuan slope is a high loess cutting slope of G209 National Road in Jixian County, Shanxi Province. During the operation, the slope becomes unstable and landslides occur. Figure 1 is the specific morphology of the landslide. The slope height is $51.6 \mathrm{~m}$, the slope degree is $51.9^{\circ}$, the slope bottom elevation is $1072 \mathrm{~m}$, the coordinates are $49483124 \mathrm{E}, 3980637 \mathrm{~N}$, the longitude and latitude are $35^{\circ} 58^{\prime} 17$ "N, $110^{\circ} 48^{\prime} 46^{\prime \prime} \mathrm{E}$.

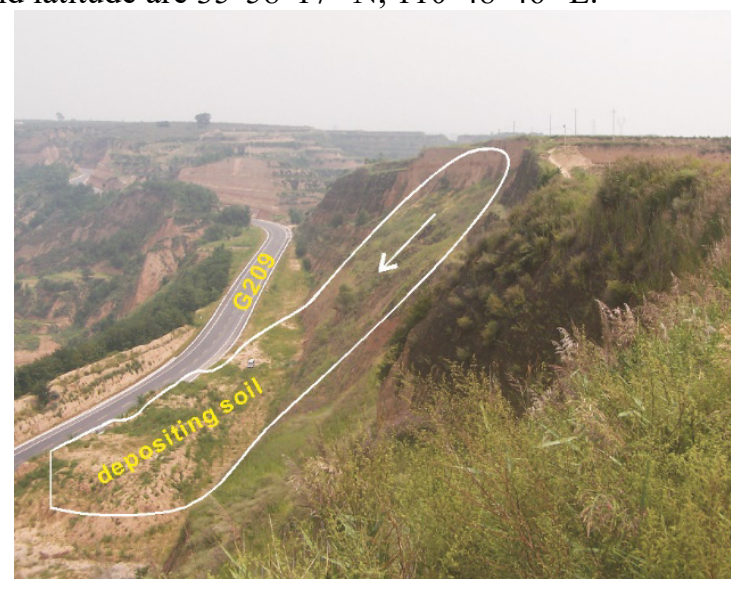

Fig. 1. The Jijiayuan landslide

Slope locate in $\mathrm{Ji}$ county. The topography and landform for the beam and gully landform of tableland, gully dense. $\mathrm{Q}_{3}, \mathrm{Q}_{2}$ and $\mathrm{Q}_{1}$ loess are developed. In most places, the outcropping of bedrock is relatively high, and groundwater seeps from the contact surface between bedrock and loess. According to the original cutting slope sections on both sides of the landslide, L5 loess is exposed from the bottom, and the upper loess palaeosol is clearly demarcated. The profile of Jijiayuan slope is shown in Fig. 2.

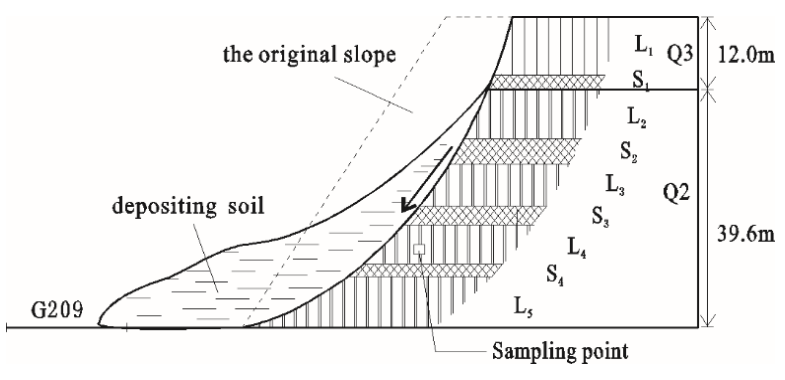

Fig. 2. The stratigraphic section

Figure 3 is according to linfen - ji county highway survey and report the results in $\mathrm{Q}_{3}$ and $\mathrm{Q}_{2}$ loess physical mechanics indexes drawn into a histogram, and 0.05 under the confidence level of normal distribution and lognormal distribution hypothesis test, the figure number $\mathrm{n}$ for the statistical sample, is not in conformity with the two kinds of distribution only marked sample number and average, conform to the distribution of the mark of the corresponding parameters.

Fig. 3 shows the physical and mechanical indicators of the stratum. Some statistical data conform to normal distribution, while a few conform to lognormal distribution. The physical and mechanical indexes of all soil layers were taken as statistical mean values, which were listed in Table 1. It is obvious that the moisture content, saturation and density increase with the formation deepening. The plastic limit moisture content is between $16 \%-20 \%$, and the average value of $\mathrm{Q}_{3} \mathrm{Q}_{2}$ and $\mathrm{Q}_{1}$ layers is $17.0 \%$. The cohesion $c$ value increases with the formation deepening, but the internal friction Angle (decreases with the formation deepening). The average value of statistical result is shown in Table. 1

Table 1. The physical properties.

\begin{tabular}{|c|c|c|c|}
\hline & $\mathrm{Q}_{3}$ & $\mathrm{Q}_{2}$ & $\mathrm{Q}_{1}$ \\
\hline $\begin{array}{c}\text { moisture content } \\
(\%)\end{array}$ & 9.2 & 17.5 & 18.9 \\
\hline $\begin{array}{l}\text { saturation } \\
(\%)\end{array}$ & 23.4 & 65.1 & 85.9 \\
\hline $\begin{array}{c}\text { plastic limit } \\
\text { (\%) }\end{array}$ & 17.0 & 17.0 & 17.4 \\
\hline $\begin{array}{l}\text { density } \\
\left(\mathrm{g} / \mathrm{cm}^{3}\right)\end{array}$ & 1.48 & 1.82 & 2.00 \\
\hline $\begin{array}{c}\text { cohesion } \\
(\mathrm{kPa})\end{array}$ & 41.2 & 54.3 & 71.5 \\
\hline $\begin{array}{l}\text { internal friction angle } \\
\qquad\left({ }^{\circ}\right)\end{array}$ & 25.2 & 24.2 & 22.9 \\
\hline
\end{tabular}



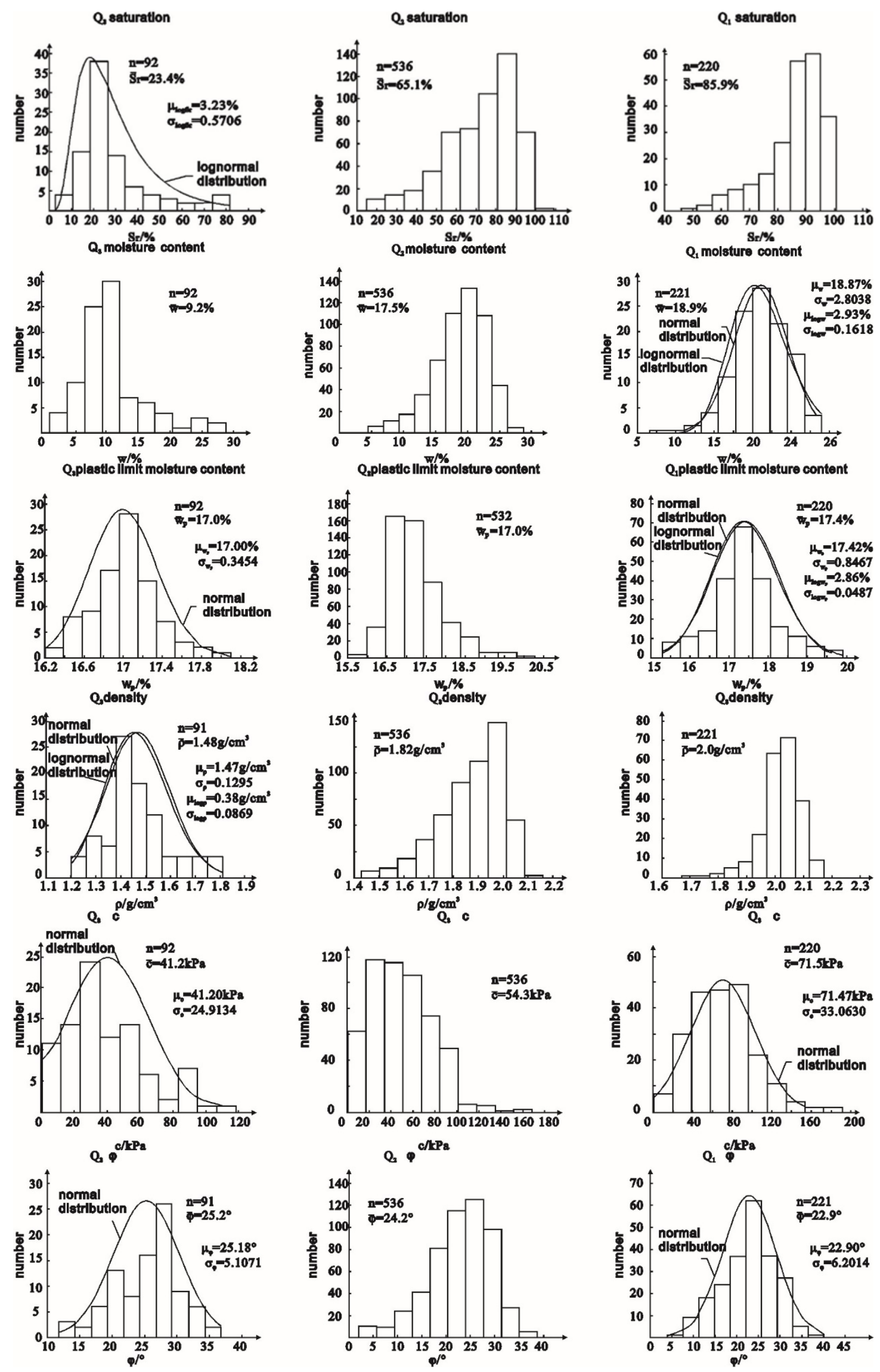

Fig. 3. The statistical of the physical properties 


\section{Inversion analysis of strength parameters}

\subsection{Calculation model}

The strata in Fig. 2 are simplified into two layers, respectively $\mathrm{Q}_{3}$ layer and $\mathrm{Q}_{2}$ layer, as shown in Fig. 4. because $\mathrm{Q}_{1}$ loess is mostly missing in this slope.

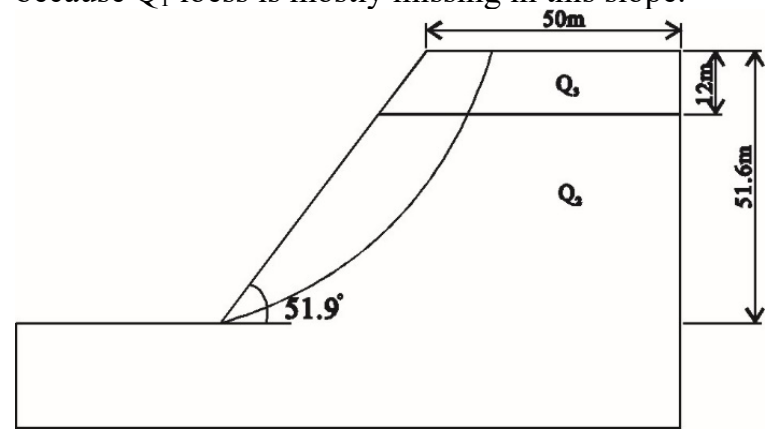

Fig. 4. The model of Jijiayuan landslide

Geostudio2007 software was used to establish the Jijiayuan slope model, and the stability coefficients were respectively used Bishop method and Spencer method in the limit equilibrium method. The data in Table 1 are used for the materials parameters of each layer. The slope stability coefficient FS $=1$ is taken as the condition to invert the values of $c$ and $\varphi$. The specific methods are as follows:

(1) The corresponding values of $\mathrm{Q}_{2}$ remain unchanged. Set the $\varphi$ of $\mathrm{Q}_{3}$ layer between $10^{\circ}$ and $30^{\circ}$, and select 5 points $\varphi=10, \varphi=15, \varphi=20, \varphi=25$, and $\varphi=30$ to carry out the inversion of $c$ value;

(2) The corresponding values $\mathrm{Q}_{3}$ remain unchanged. Set the $\varphi$ of $\mathrm{Q}_{2}$ layer between $10^{\circ}$ and $30^{\circ}$, and select five points $\varphi=10, \varphi=15, \varphi=20, \varphi=25$, and $\varphi=30$ to carry out the inversion of $c$ value;

\subsection{Analysis of results}

Figure 5 shows the inversion analysis results of strength parameters of $\mathrm{Q}_{3}$. The $\varphi$ value of the $\mathrm{Q}_{3}$ loess in the upper layer of the slope changes, while the $\mathrm{c}$ value remains basically unchanged. The variation of the $\varphi$ value of the strength parameter of the $\mathrm{Q}_{3}$ loess has little influence on the overall stability of the slope.

Figure 6 shows the inversion analysis results of strength parameters of $\mathrm{Q}_{2}$. However, the c value of the lower $\mathrm{Q}_{2}$ loess decreases sharply with the decrease of the $\varphi$ value, indicating that the change of the strength parameter $\varphi$ value of the $\mathrm{Q}_{2}$ loess layer has a greater impact on the slope stability.

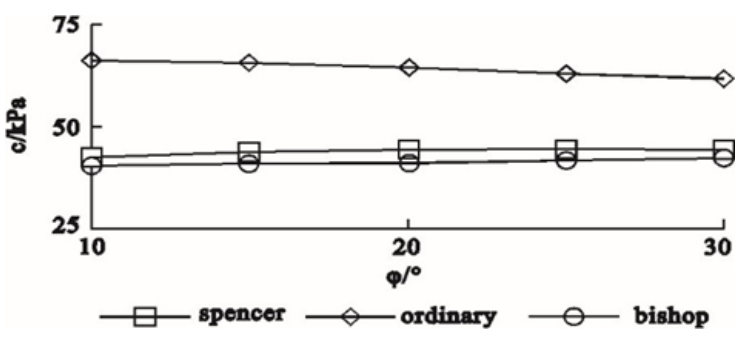

Fig. 5. The inner friction angle and cohesion curve of $\mathrm{Q}_{3}$

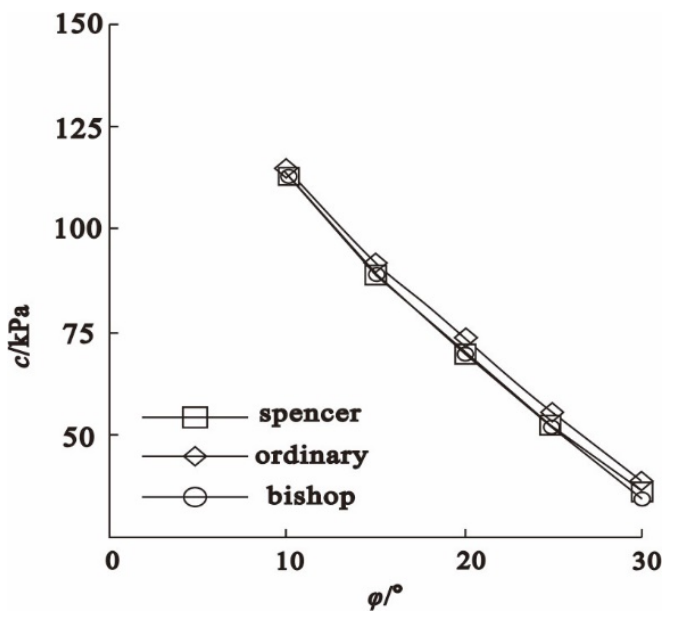

Fig. 6. The inner friction angle and cohesion curve of $\mathrm{Q}_{2}$

The Sigma /W module of Geostudio2007 software was used to carry out the finite element analysis on the slope with the determined sliding surface, and the stress state of the sliding surface in the limit equilibrium analysis was obtained. The normal stress of the sliding surface was calculated. Fig. 13 is the relationship curve between the vertical height of the sliding surface and $\sigma \tan \varphi$ with the slope foot as the origin.

With the increase of the vertical height of the sliding surface, the influence of $\varphi$ on the stability of the slope gradually increases to the maximum value first, and then begins to decrease gradually. At $20 \mathrm{~m}$ downward from the top of the slope, $(\tan (/ \mathrm{c}=1$, indicating that cohesion and internal friction Angle play an equal role here. Thus, it can be proved that the $c$ value plays a role against the shear strength of the low slope within $20 \mathrm{~m}$, and the lower the slope is, the smaller the effect of $\varphi$ value is. For the high slope above $20 \mathrm{~m}, \varphi$ plays a major role in resisting shear strength, and the higher the slope is, the less the effect of $c$ value is. The results of the two methods show that the Bishop method and Spencer method are basically the same for the circular slope of pure loess under various calculation conditions. 

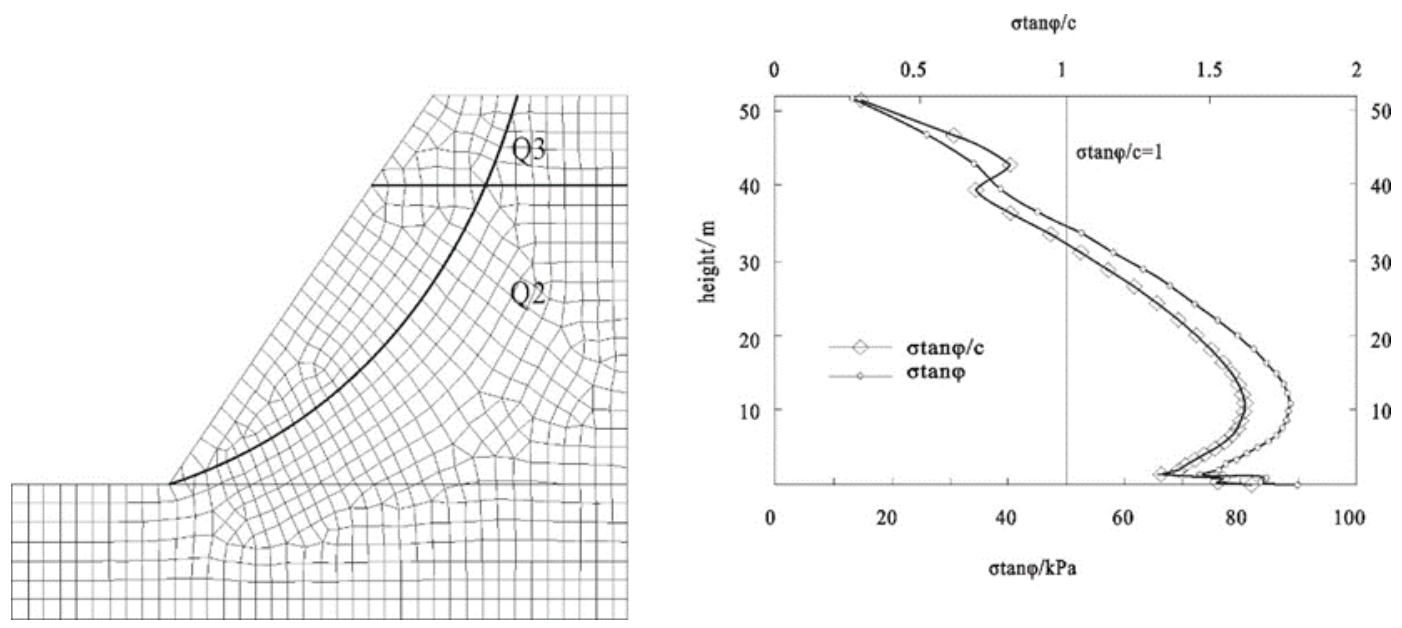

Fig. 7. The contribution of $\mathrm{c}$ and values to the stability of slopes under different height of slide face

\section{Conclusion}

The determination of cohesion $c$ is a key problem in the stability evaluation of slope and landslide engineering. The value of loess cohesion $c$ is large, and with high variability, so it is difficult to obtain. The conclusion can be drawn from the inversion analysis of "limit state slope" and the finite element stress analysis of sliding surface.

The normal stress on the sliding surface increases, and $\varphi$ plays a controlling role on the slope stability; When the normal stress is small, the value of $c$ can be fully exerted to control the stability of the slope. In the case of Jijiayuan landslide, when the depth of the sliding surface is about $20 \mathrm{~m}, c$ and $\varphi$ have equal effect on the stability of the slope. Therefore, when calculating the slope stability in practical engineering, the soil $c$ value is mainly considered for the lower slope. For the higher slope, the soil $\varphi$ value is considered.

\section{References}

1. C.C. Han, Y.X. Han, The research of slope stability analysis method and developing trend, energy Environmental Protection, 29 (2015)

2. J. Li, X.H. Zhou, J.Q. Dang. Graphic method for the stability of loess slopes. Chinese J of Geotech. Eng., 20 (1998)

3. Z.Y. Chen, Limit analysis for the classic problems of soil mechanics. Chinese J of Geotech. Eng.,24 (2002)

4. Y.Q. Qin, H. Tang, Z.Y. Feng, et al.Slope stability evaluation by clustering analysis. Rock Soil Mech., 39 (2018)

5. R.W.M. Cheung, W.H. Tang. Reliability of Deteriorating Slopes. J. Geotech. Eng., 131 (2005)

6. G.H. Wu, W. Ma, Y.S. Wang. Slope stability analysis of fuzzy comprehensive evaluation, Ground Water, 36 (2014)

7. H.J. Huang, J.K. Chen, D.Wang, et al. Analysis of Effect of Strength Parameters on Reliability Index of Soil Slope Stability. Journal of Yangtze River Scientific Research Institute, 26(2009)

8. K. Karnagh, R.W. Clough, Finite element application in characeringation of elastic solid. Int. J. Solids Struct., 7(1972)

9. Gioda G, Locatelli L.Back analysis of the measurements performed during the excavation a shallow tunnel in sand, Int. J. Numer. Anal. Methods Geomech., 23(1999)

10. S. Sakurai, K. Takeuchi Back analysis of measured displacement of tunnel. Rock Mech and Rock Eng., 16 (1983)

11. B.C. Chen, J. Ling. Application of inverse analysis on landslide stability. Cities and Towns Construction in Guangxi, 10 (2005)

12. H.T. Wang, Y.M. Zang, J.X. Liu. The inverse analysis of soil mechanics parameters and the stability analysis of slope in Magang new area. Geotechnical Engineering World, 11(2008)

13. Y.F. Gong, C.B. Zhou, Y. Liang, et al. Application of parameter back analysis method to deformation and stability analysis of rock high slope. Rock Soil Mech.,23(2002)

14. P. Li, B.G.Wang, T.L. Li. Study on Analogism Used in Highway Cutting Loess Slope Design. J. Highw. Transp. Res. Dev.,26(2009) 